\title{
Pengaruh Sistem Pengapian Capasitive Discharge Ignition(CDI) dengan Sumber Arus yang Berbeda Terhadap Kandungan Karbon Monoksida (CO) Gas Buang Sepeda Motor 110 cc
}

\author{
Imam Mahir \\ Jurusan Teknik Mesin, Fakultas Teknik, Universitas Negeri Jakarta \\ Jalan Rawamangun Muka, Jakarta \\ imammahir@yahoo.com
}

\begin{abstract}
Abstrak
Sistem pengapian pada motor bakar merupakan prasyarat untuk terjadinya pembakaran dan juga menentukan kualitas dari proses pembakaran tersebut. Persyaratan utama dari sistem pengapian adalah mampu mensuplai energi panas yang dibutuhkan dalam bentuk percikan bunga api listrik busi pada volume yang kecil dan waktu yang cukup untuk terjadinya pembakaran. Bebagai jenis sistem pengapian dikembangkan untuk berbagai keperluan dan hasil yang berbeda sesuai dengan kebutuhan. Metode penelitian yang digunakan adalah metode eksperimental. Objek penelitian ini adalah mengukut kadar kandungan karbon monoksida (CO) gas buang yang dihasilkan oleh sepeda motor 4 langkah 110ccdengan sistem pengapian CDI dengan sumber arus AC (CDI-AC) dan sumber arus DC (CDI-DC) yang diuji dalam berbagai putaran mesin (RPM) yang berbeda.Dari hasil penelitian didapatkan nilai rata-rata kandungan $\mathrm{CO}$ gas buang yang dihasilkan pada sistem pengapian CDI-AC adalah sebasar 6,91\%, sedangkan rata-rata pada sistem pengapian CDI-DC adalah 7,07\%. Berdasarkan temuan ini persentase ratarata kandungan $\mathrm{CO}$ pada gas buang sistem pengapian CDI-DC lebih tinggi dibandingkan persentase rata-rata CDI-AC, namun fluktuasi kadar $\mathrm{CO}$ pada sistem CDI-DC lebih kecil dibandingkan CDI-AC pada berbagai RPM yang berbeda. Hal ini sesuai dengan karakteristik sistem pengapian CDI-DC yang menghasilkan tegangan lebih stabil sehingga gas $\mathrm{CO}$ yang dihasilkan dari pembakaran juga lebih stabil dibandingkan sistem pengapian CDI AC.
\end{abstract}

Keywords: Sistem pengapian CDI, sumber arus AC \& DC, karbon monoksida 


\section{Pendahuluan}

Sistem pengapian yang diterapkan pada sepeda motor dapat dibedakan atas sistem pengapian baterai (battery-coil ignition), sistem pengapian magnet (magneto ignition system), dan sistem pengapian elektronik (electronic ignition system). Sistem pengapian baterai dan magneto hanya dibedakan pada sumber energi listrik. Sistem pengapian baterai menggunakan baterai sebagai sumber sistem pengapian magnet menggunakan generator tegangan rendah sebagai sumber teganga. Sedangkan sistem pengapian elektronik menggunakan komponen elektronik seperti transistor maupun unit CDI (Capasitive Discharge Ignition) sebagai pemutus tegangan primer untuk menghasilkan tegangan tinggi pada busi. Sistem pengapian elektronik ini mampu bekerja dengan lebih baik dibanding dengan sistem konvensional, karena api yang dihasilkan lebih besar baik pada putaran lambat maupun putaran tinggi (Stone, 2004).

Sistem pengapian pada sebuah motor bakar pada dasarnya berfungsi untuk mengubah campuran kimia dari unsur hidrogen dan karbon didalam bahan bakar dengan oksigen yang ada diudara menjadi energi panas yang selanjutnya berguna untuk menghasilkan energi mekanis. (Mathur; Sharma, 1980: 138). Energi panas dalam bentuk percikan api listrik pada busi diberikan saat campuran bahan bakar dan udara siap untuk terjadinya pembakaran yang biasa disebut saat pengapian. Saat pengapian pada sepeda motor berlangsung antara $15^{\circ}$. $30^{\circ}$ sebelum titik mati atas (TMA). Proses pemasukan bahan bakar tidak terjadi sekaligus melainkan terjadi secara bertahap yaitu dimulai $25^{\circ}$ poros engkol sebelum TMA dan berakhir $45^{\circ}$ setelah torak melalui TMB.

Prinsip kerja sistem pengapian CDI adalah dengan memamfaatkan komponenkomponen elektronik untuk membangkitkan arus tegangan tinggi dan mengatur saat pengapiannya, sehingga sistem kerja rangkaian ini lebih lembut, efektif dan efisien.Sistem pengapian elektronik dengan CDI sendiri telah mengalami perkembangan ditinjau dari sumber arus yang digunakan yaitu sistem pengapian CDI dengan arus AC (Alternating Current) dan sistem pengapian CDI dengan arus DC (Direct Current).

\section{Sistem pengapian $\mathrm{CDI}$ dengan arus $\mathrm{AC}$}

Sistem pengapian CDI-AC merupakan sistem pengapian pengganti sistem konvensional dan telah banyak digunakan pada sepeda motor. Sistem ini menggunakan arus listrik AC yang dihasilkan oleh alternator.Rangkaian sistem pengapian CDI dapat dilihat pada gambar berikut:

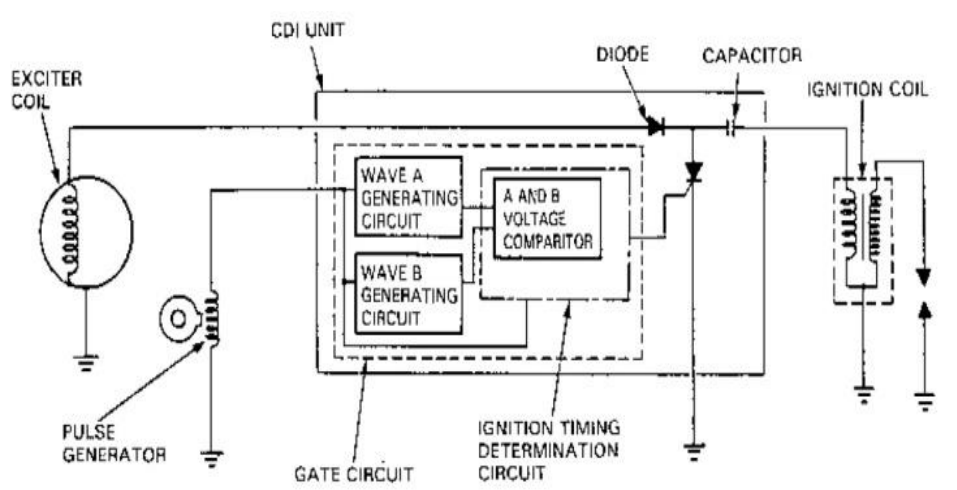

Gambar 1. Sirkuit Sistem Pengapian CDI$\mathrm{AC}$

(Honda Motor, 1988:23-5)

Adapun cara kerja sistem pengapian CDI-AC adalah apabila magnet berputar, maka koil eksitasi (exciter coil) akan menghasilkan arus yang dialirkan ke dioda (D), kemudian ke kapasitor (C) untuk disimpan sementara. Pada saat yang bersamaan koil pulsa (pulse generator) juga menghasilkan arus listrik yang kemudian mengaktifkan SCR (Silicon Control Rectifier). Aktifnya SCR memicu arus yang tersimpan dalam kapasitor mengalir kekumparan primer koil pengapian. Seketika itu juga terjadilah arus induksi pada kumparan sekunder koil, yang kemudian menghasilkan loncatan bunga api pada busi. 
Terjadinya tegangan tinggi pada koil pengapian adalah saat koil pulsa dilewati oleh magnet, ini berarti bahwa waktu pengapian (ignition timing) ditentukan oleh penetapan posisi koil pulsa. Sehingga sistem CDI tidak memerlukan penyetelan waktu pengapian seperti pada pengapian konvensional. Pemajuan saat pengapian terjadi secara otomatis yaitu saat pengapian dimajukan dengan bertambahnya tegangan pada koil pulsa akibat kecepatan putaran rotor.

Beberapa keuntungan dari sistem pengapian CDI dibanding sistem pengapian konvensional adalah:

1. Dapat menghasilkan output tegangan tinggi meskipun pada range penyalaan tinggi pada putaran tinggi.

2. Tahanan internal sangat kecil (sekitar 50 ohm) yang memungkinkan terjadi kenaikan tegangan lebih cepat.

3. Pemeliharaan lebih jarang dan masa pakainya lebih lama, karena kemungkinan aus pada titik kontak seperti platina tidak ada.

4. Mesin mudah distar, karena tidak tergantung pada kondisi platina.

5. Tegangan output relatif tergantung oleh putaran mesin sehingga mengurangi adanya misfiring meskipun terjadi gangguan pada busi (Mathur\& Sharma, 1980: 380-381).

Adapun kelemahan sistem pengapian CDI adalah dikarenakan cepatnya pengosongan kapasitor (discharging) menghasilkan percikan api busi kuat namun singkat (sekitar 0,1 milidetik). Hal ini dapat mengakibatkan sulitnya penyalaan khususnya pada rasio campuran kaya.

\section{Sistem Pengapian CDI dengan arus DC}

Sistem pengapian CDI-DC merupakan sistem yang baru dan hanya sepeda motor tertentu yang sudah menggunakannya. Sesuai dengan namanya DC (Direct Current) yang berarti arus searah, maka sistem pengapian ini menggunakan arus yang bersumber dari baterai. Baterai mampu mengeluarkan tegangan yang stabil berbeda dengan tegangan yang dihasilkan oleh generator yang selalu berubah sesuai putaran mesin. Hal tersebut menyebabkan tegangan yang masuk kedalam CDI menjadi lebih konstan, dan mengakibatkan umpan balik kekoil juga stabil, dan api yang dihasilkan dari sistem pengapian dengan CDI-DC ini lebih besar.

Jalur kelistrikan pada sistem pengapian dengan sumber arus DC ini adalah: arus pertama kali dihasilkan oleh kumparan pengisian akibat putaran magnet yang selanjutnya disearahkan dengan menggunakan rectifier (cuprok) kemudian dihubungkan kebaterai untuk melakukan proses pengisian (Charging System), dari baterai arus ini seterusnya dihubungkan kekunci kontak, CDI unit, koil dan busi. Untuk lebih jelasnya perhatikan gambar sirkuit sistem pengapian CDI-DC berikut:

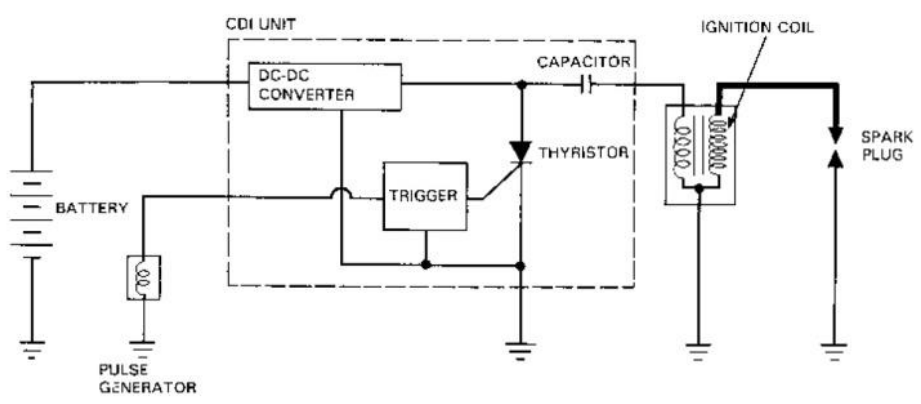

Gambar 2. Sirkuit Sistem PengapianCDIDC

(Honda Motor,1988: 23-7).

Cara kerja sistem pengapian CDIDCyaitu pada saat kunci kontak di on kan arus akan mengalir dari baterai menuju sakelar, bila sakelar on maka arus akan mengalir ke kumparan penguat arus dalam CDI yang meningkatkan tegangan dari baterai (12 volt DC menjadi 220 volt AC), 
selanjutnya arus disearahkan melalui dioda kemudian dialirkan ke kapasitor untuk disimpan sementara. Karena putaran mesin menyebabkan koil pulsa menghasilkan arus yang kemudian mengaktifkan SCR, dengan aktifnya SCR memicu kapasitor mengalirkan arus ke kumparan primer koil pengapian yang kemudian menimbulkan arus induksi pada kumparan skunder, sehingga tercipta loncatan bunga api pada busi.

\section{Karbon Monoksida (CO)}

Emisi gas buang adalah zat atau unsur yang dihasilkan oleh proses pembakaran dalam ruang bakar yang dibuang keudara bebas. Emisi ini bisa ditimbulkan dari penguapan tangki bahan bakar, blow by dari ruang bakar, dan gas buang sisa pembakaran. Polutan udara yang terutama dihasilkan oleh motor bakar diantaranya karbon monoksida (CO), hidrokarbon tidak terbakar (UBHC), nitrogen oksida $\left(\mathrm{NO}_{\mathrm{x}}\right)$, timbal, dan partikel emisi lainnya.

Emisi gas dan partikel-partikel yang diatur kadarnya oleh regulasi sebagai hasil dari pembakaran tidak sempurna adalah:

(a) Karbon monoksida (CO) adalah gas beracun tinggi yang tidak berbau.

(b) Karbon (C) yang biasanya muncul dalam bentuk asap.

(c) Hidrokarbon ( $\mathrm{HC}$ atau TotalHC) merupakan fraksi yang tidak terbakar dan bahan bakar cair.

(d) Nitric oxide (NO) dan nitrogen dioxide $\left(\mathrm{NO}_{2}\right)$ bergabung menjadi $\mathrm{NO}_{x}$ (Martyr and Plint, 2007:325-326).

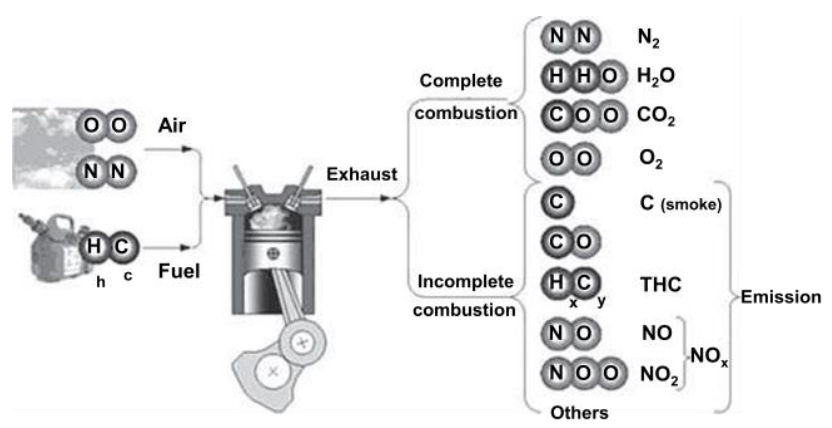

Gambar 3. Komponen Gas pada Proses

Pembakaran

(Martyr and Plint, 2007:325)

Secara aktual proses pembakaran sempurna tidak pernah terjadi, sehingga mengakibatkan terbentuknya gas karbon monoksida (CO) dan unsur lain yang sangat berbahaya. Emisi karbon monoksida (CO) dari motor pembakaran dalam pada dasarnya ditentukan oleh komposisi rasio bahan bakar dan udara (Heywood, 1988:592).

Kandungan emisi gas buang dipengaruhi oleh perubahan komposisi campuran udara dan bahan bakar (air-fuel ratio) seiring perubahan putaran mesin.

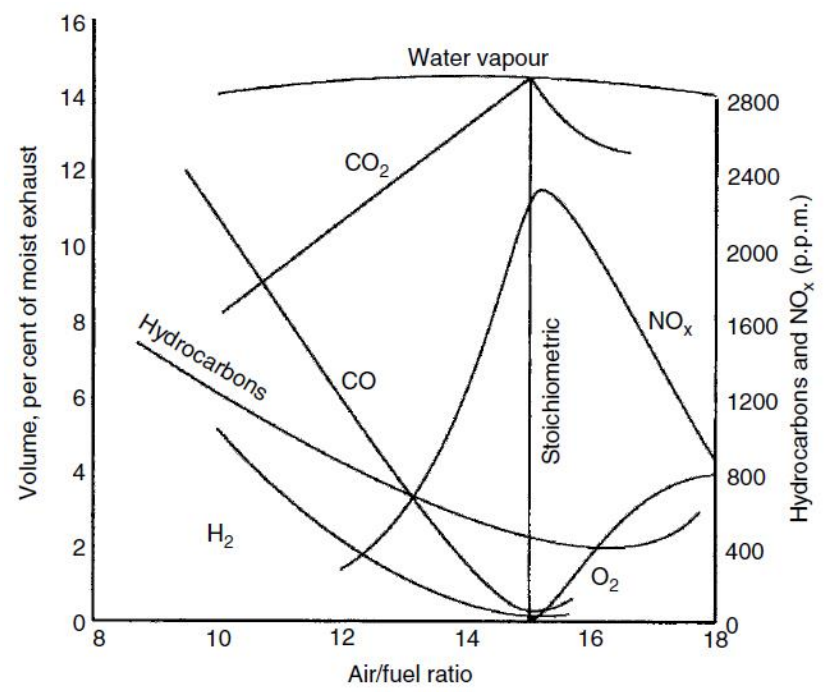

Gambar 4. Hubungan antara air-fuel ratio dengan kandungan emisi gas buang motor bensin

(Martyr and Plint, 2007:327) 
Pulkrabek (1997:285) menyatakan bahwa karbon monoksida merupakan gas beracun yang tidak berwarna dan tidak berbau, dihasilkan oleh engine yang bekerja pada campuran bahan bakar dan udara kaya. Ketika pada proses pembakaran jumlah oksigen tidak tercukupi untuk mengkonversi karbon menjadi $\mathrm{CO}_{2}$, beberapa bahan bakar tidak terbakar dan kemudian beberapa karbon berakhir menjadi CO.

Selain komposisi campuran bahan bakar dan udara berpengaruh pada emisi, sistem pengapian juga dapat mempengaruhi kadar gas buang yang dihasilkan dari proses pembakaran. Desain dan letak busi, durasi dan energi percikan busi baik single maupun multiple busi, semuanya berpengaruh kepada pembakaran dan emisi yang dihasilkan, demikian halnya juga saat pengapian berpengaruh kuat pada konsumsi bahan bakar dan emisi gas buang (Martyr and Plint, 2007:327).

\section{Metoda Eksperimen dan Fasilitas yang Digunakan}

Penelitian ini menggunakan metode penelitian eksperimental. Perlakuan yang diberikan pada sepeda motor bensin 4 langkah 110cc adalah dengan melakukan variasi pada sistem pengapian jenis CDI dengan sumber arus yang berbeda yaitu arus AC dan DC. Kemudian data yang diambil adalah kandungan karbon monoksida (CO) pada gas buang sepeda motor dengan sistem pengapian CDI dengan sumber arus AC dan DC. Fasilitas yang dibutuhkan dalam penelitian ini adalah:

1. Tachometer, untuk mengukur putaran kerja mesin pada berbagai kecepatan.

2. CO Tester (Four Gas Analyzer) untuk mengetahui kadar $\mathrm{CO}$ yang dikandung oleh gas buang.

3. Unit sepeda motor 4 langkah 110cc.

4. Unit CDI DC sebagai pembanding CDI standar (CDI dengan sumber arus AC).

\section{Hasil dan Pembahasan}

Berikut ini adalah uraian data tentang jumlah kandungan karbon monoksida gas buang yang dihasilkan oleh sepeda motor yang diperoleh dalam penelitian.

Tabel 1. Kandungan Karbon Monoksida (CO) Gas Buang Sepeda Motor 110 cc

\begin{tabular}{|c|c|c|c|c|c|c|}
\hline \multirow[t]{2}{*}{ RPM } & \multicolumn{3}{|c|}{$\begin{array}{c}\text { Hasil Pengujian } \\
\text { Sistem Pengapian } \\
\text { CDI Dengan } \\
\text { Sumber Arus AC } \\
(\%)\end{array}$} & \multicolumn{3}{|c|}{$\begin{array}{c}\text { Hasil Pengujian } \\
\text { Sistem Pengapian } \\
\text { CDI Dengan } \\
\text { Sumber Arus DC } \\
(\%)\end{array}$} \\
\hline & $\begin{array}{c}\mathrm{Ke}- \\
1\end{array}$ & $\mathrm{Ke}-2$ & $\begin{array}{c}\text { Rera } \\
\text { ta }\end{array}$ & $\begin{array}{c}\mathrm{Ke}- \\
1\end{array}$ & $\mathrm{Ke}-2$ & $\begin{array}{c}\text { Rera } \\
\text { ta }\end{array}$ \\
\hline 1400 & 7,89 & 8,05 & 7,97 & 6,78 & 7,85 & 7,31 \\
\hline 2000 & 7,36 & 7,16 & 7,26 & 7,03 & 7,71 & 7,37 \\
\hline 2600 & 6,91 & 7,04 & 6,97 & 7,17 & 7,37 & 7,27 \\
\hline 3200 & 6,17 & 6,54 & 6,35 & 6,63 & 7,07 & 6,85 \\
\hline 3800 & 6,14 & 5,91 & 6,02 & 5,69 & 7,41 & 6,55 \\
\hline
\end{tabular}

Nilai hasil pengujian pertama kandungan karbon monoksida gas buang yang dihasilkan oleh sistem pengapian CDI yang menggunakan sumber arus AC dan DC dapat dilihat pada grafik sebagai berikut:

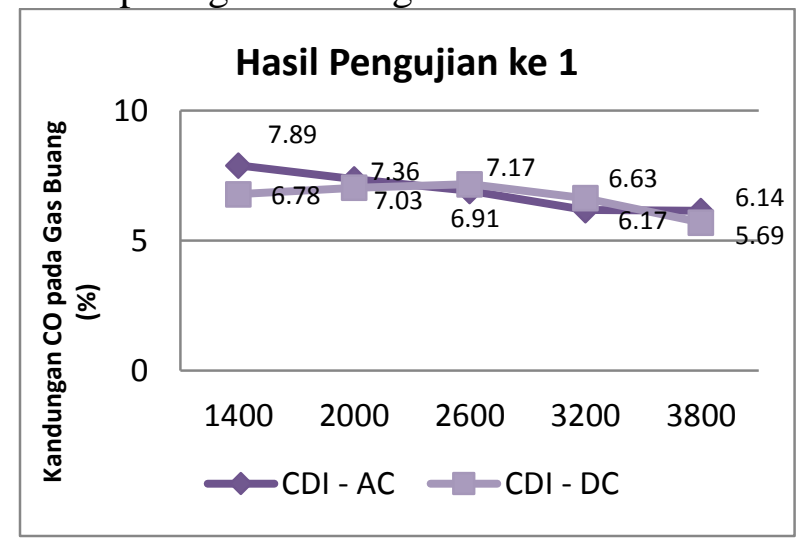

Gambar 5.Grafik hasil pengujian ke-1 kandungan $\mathrm{CO}$ pada gas buang. 
Berdasarkan gambar 5 di atas terlihat kandungan $\mathrm{CO}$ pada sistem pengapian CDI dengan sumber arus AC dan DC pada hasil pengujian 1 terlihat perbedaan yang cukup signifikan. Pada putaran $1400 \mathrm{rpm}$ terlihat bahwa sistem pengapian CDI-DC dapat lebih baik dari sistem pengapian CDI-AC dimana kadar $\mathrm{CO}$ yang dihasilkan lebih rendah, sementara untuk putaran menengah $\mathrm{CO}$ yang dihasilkannya lebih tinggi.

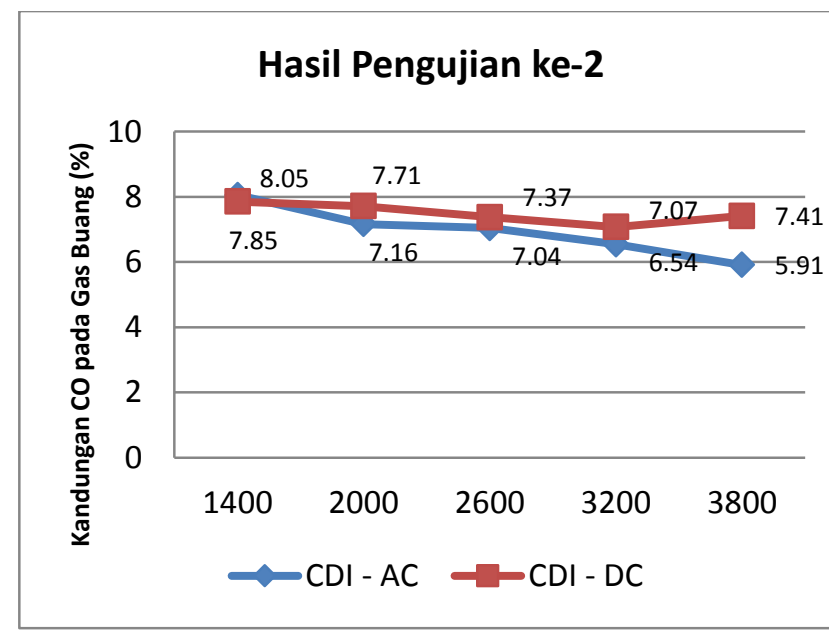

Gambar 6.Grafik hasil pengujian ke-2 kandungan $\mathrm{CO}$ pada gas buang.

Berdasarkan gambar 6 di atas terlihat kandungan $\mathrm{CO}$ pada sistem pengapian $\mathrm{CDI}$ dengan sumber arus AC dan DC pada hasil pengujian 2 terlihat perbedaan yang cukup signifikan pada putaran menengah dan putaran tinggi. Dan nilai rata-rata kandungan karbon monoksida gas buang yang dihasilkan oleh sepeda motor yang menggunakan sistem pengapian CDI dengan sumber arus DC adalah sebagai berikut:

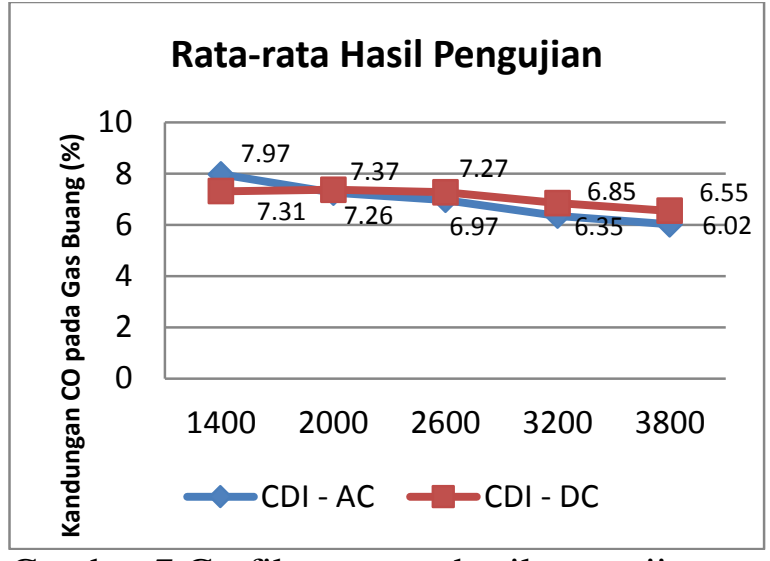

Gambar 7.Grafik rata-rata hasil pengujian kandungan $\mathrm{CO}$ pada gas buang

Berdasarkan gambar 7, diketahui ratarata jumlah kandungan karbon monoksida gas buang pada sepeda motor dengan menggunakan sistem pengapian CDI-AC adalah 6,914\%. Sedangkan rata-rata kandungan karbon monoksida gas buang yang dihasilkan oleh sepeda motor dengan menggunakan sistem pengapian CDI-DC adalah $7,07 \%$. Sehingga didapat perbedaan antara keduanya adalah $0,156 \%$. Dengan kandungan karbon monoksida gas buang yang dihasilkan oleh sepeda motor yang menggunakan sistem pengapian CDI-DC lebih besar dibanding kandungan karbon monoksida yang dihasilkan oleh sepeda motor yang menggunakan sistem pengapian CDI-AC.

Dari gambar 7 juga terlihat bahwa sistem pengapian CDI-DC dapat lebih baik dari sistem pengapian CDI-AC yaitu pada putaran $1400 \mathrm{rpm}$, sementara untuk putaran menengah dan tinggi karbon monoksida yang dihasilkan sistem pengapian CDI-DC tinggi. Secara teoritis energi percikan api busi pada sistem pengapian CDI-DC tidak dipengaruhi oleh putaran mesin, sehingga meskipun putaran mesin rendah suplai arus dari baterai ke CDI konstan, sehingga proses pembakaran pun cenderung lebih stabil dan kadar CO yang dihasilkan cenderung tidak fluktuatif. 
Secara teoritis pembentukan karbon monoksida oleh motor bakar diantaranya dikarenakan komposisi campuran udara dan bahan bakar yang kaya yang umumnya terjadi pada putaran idle atau rendah dan saat setelah melakukan akselerasi (penutupan throttle). Pada saat putaran menengah dan putaran tinggi terlihat sistem pengapian CDI$\mathrm{AC}$ menghasilkan $\mathrm{CO}$ yang lebih rendah dibandingkan sistem pengapian CDI-DC. Kondisi tersebut disebabkan karena sistem pengapian AC dipengaruhi oleh kecepatan putaran dari mesin sehingga akibat putaran yang tinggi maka suplai arus yang masuk ke CDI juga besar dan efeknya pembakaran yang dihasilkan lebih sempurna.

Sedangkan pada sistem pengapian CDI-DC meskipun terjadi penurunan untuk setiap tahap putaran mesin namun kadar karbon monoksida yang dihasilkan masih lebih besar dari sistem pengapian CDI-AC. Pada sistem pengapian CDI-AC penurunan kadar $\mathrm{CO}$ maksimal diperoleh pada putaran $3800 \mathrm{rpm}$ dengan kadar karbon monoksida sebesar $6,02 \%$, sedangkan penurunan kadar $\mathrm{CO}$ terbaik pada sistem pengapian CDI-DC juga terjadi pada putaran $3800 \mathrm{rpm}$ yaitu sebesar $6,55 \%$.

\section{Kesimpulan}

Penggantian sistem pengapian standar yang digunakan pada sepeda motor 4 langkah 100cc yaitu sistem pengapian CDI dengan sumber arus AC diubah menjadi sistem pengapian CDI dengan sumber arus DC ternyata berpengaruh terhadap kandungan karbon monoksida ( $\mathrm{CO}$ ) yang dihasilkan dari proses pembakaran. Berdasarkan rata-rata hasil pengujian pada sistem pengapian CDIAC kandungan $\mathrm{CO}$ tertinggi terjadi pada putaran $1400 \mathrm{rpm}$ yaitu sebesar 7,97\%, sedangkan hasil terendah terjadi pada putaran $3800 \mathrm{rpm}$ dengan $6,02 \%$. Sementara untuk sistem pengapian CDI-DC hasil tertinggi terjadi pada putaran 2000 rpm yaitu sebesar
$7,37 \%$, dan hasil terendah terjadi pada putaran 3800 dengan $6,55 \%$.

Nilai rata-rata kandungan $\mathrm{CO}$ gas buang yang dihasilkan pada sistem pengapian CDI-AC adalah sebasar $6,91 \%$, sedangkan rata-rata pada sistem pengapian CDI-DC adalah $7,07 \%$. Berdasarkan temuan ini persentase rata-rata kandungan $\mathrm{CO}$ pada gas buang sistem pengapian CDI-DC lebih tinggi dibandingkan persentase rata-rata CDI-AC, namun fluktuasi kadar CO pada sistem CDIDC lebih kecil dibandingkan CDI-AC pada berbagai RPM yang berbeda. Hal ini sesuai dengan karakteristik sistem pengapian CDIDC yang menghasilkan tegangan lebih stabil sehingga gas $\mathrm{CO}$ yang dihasilkan dari pembakaran juga lebih stabil dibandingkan sistem pengapian CDI AC.

\section{Referensi}

Heywood, Jhon B. Internal Combustion Engine Fundamentals. New York: McGrawHill, Inc. (1988).

Martyr, A.J. \& Plint, M.A. Engine Testing. Theory and Practice. Third Edition. Oxford: Butterworth - Heinemann. (2007).

Mathur, M.L. \& Sharma, R.P. A Course in Internal Combustion Engines. Delhi: Dhanpat Rai \& Sons. (1980).

Pulkrabek, Williard. W. Engineering Fundamentals of The Internal Combusion Engine. New Jersey: Prentice Hall. (1997).

Stone, Richard \& Ball, Jeffrey K. Automotive Engineering Fundamentals. USA: SAE. (2004). 